\title{
Protecting the aged heart during cardiac surgery: Use of del Nido cardioplegia provides superior functional recovery in isolated hearts
}

\author{
Arun Govindapillai, BSc, ${ }^{\mathrm{a}}$ Rui Hua, PhD, ${ }^{\mathrm{a}}$ Robert Rose, $\mathrm{PhD},{ }^{\mathrm{a}}$ Camille Hancock Friesen, $\mathrm{MD},{ }^{\mathrm{b}, \mathrm{c}, \mathrm{d}}$ and \\ Stacy B. O’Blenes, MD ${ }^{\mathrm{a}, \mathrm{b}, \mathrm{c}}$
}

\begin{abstract}
Objectives: Aged hearts are particularly vulnerable to ischemia-reperfusion injury. Our objective was to determine if del Nido cardioplegia, which contains lidocaine, less blood, and less calcium than our standard cardioplegia, provides superior protection for aged hearts. We also sought to determine if the lidocaine in del Nido cardioplegia is adequate to prevent $\mathrm{Na}^{+}$influx via the window current.
\end{abstract}

\begin{abstract}
Methods: Sodium channel kinetics were measured in rat cardiomyocytes with and without lidocaine. Recovery after 60 minutes of cardioplegic arrest was assessed in isolated working senescent rat hearts. Del Nido cardioplegia was delivered as a single dose $(n=8)$ because it is used clinically, and standard cardioplegia was delivered as an induction dose with re-dosing every 20 minutes $(\mathrm{n}=8)$. After 20 minutes of reperfusion, hearts were switched to working mode for 60 minutes. Flows were indexed to ventricular dry weight. Troponin release was assayed.
\end{abstract}

Results: Sodium channel kinetics indicated that the lidocaine concentration in del Nido cardioplegia minimizes the potential for $\mathrm{Na}+$ influx via the window current. Spontaneous contractions occurred in fewer hearts arrested with del Nido cardioplegia ( $88 \%$ vs $13 \% ; P=.01)$, and troponin release was reduced $(0.24 \mathrm{vs} 0.89 \mathrm{ng} / \mathrm{mL}$; $P=.017$ ). Cardiac output was approximately $90 \%$ of baseline in the del Nido group compared with approximately $50 \%$ in the standard group $\left(173 \pm 14 \mathrm{vs} 86 \pm 22 \mathrm{~mL} \cdot \min ^{-1} \cdot \mathrm{g}^{-1} ; P=.0008\right)$. Stroke work was higher in the del Nido group (93 \pm 6 vs $\left.41 \pm 10 \mathrm{~mL} \cdot \mathrm{mm} \mathrm{Hg} \cdot \mathrm{g}^{-1} ; P=.0002\right)$.

Conclusions: Del Nido cardioplegia prevents spontaneous contractions during arrest, reduces troponin release, and results in superior myocardial function in isolated aged hearts. Del Nido cardioplegia has the potential to provide superior myocardial protection for older patients undergoing cardiac surgery. (J Thorac Cardiovasc Surg 2013;146:940-8)

The growing number of elderly patients requiring cardiac surgery is an important group at higher risk for cardiac dysfunction and death postoperatively. ${ }^{1,2}$ Aged hearts are particularly susceptible to reperfusion injury after the ischemic periods that occur during cardiac surgery ${ }^{3-5}$ owing to changes in the way cardiomyocytes deal with intracellular $\mathrm{Ca}^{2+}$, particularly during ischemia. ${ }^{5-8}$

Del Nido cardioplegia is used in several centers for myocardial protection during pediatric cardiac surgery. ${ }^{9-11}$ Compared with the standard 4:1 blood cardioplegia we use in our adult practice, del Nido cardioplegia is more dilute (1:4 blood:crystalloid), has approximately $75 \%$ less

From the Departments of Physiology and Biophysics, ${ }^{\mathrm{a}}$ Surgery, ${ }^{\mathrm{c}}$ Pathology, ${ }^{\mathrm{d}}$ Dalhousie University, and IWK Health Centre, ${ }^{\mathrm{b}}$ Halifax, Nova Scotia, Canada.

Supported by grants form the Canadian Institutes for Health Research and the Heart and Stroke Foundation of Nova Scotia. Robert Rose is supported by a Canadian Institutes for Health Research New Investigator Award.

Disclosures: Authors have nothing to disclose with regard to commercial support.

Read at the 93rd Annual Meeting of The American Association for Thoracic Surgery, Minneapolis, Minnesota, May 4-8, 2013.

Received for publication April 18, 2013; revisions received May 16, 2013; accepted for publication May 20, 2013; available ahead of print Aug 19, 2013.

Address for reprints: Stacy B. O'Blenes, MD, IWK Children's Heart Centre, IWK Health Centre, 5850/5980 University Ave, PO Box 9700, Halifax, Nova Scotia B3K 6R8, Canada (E-mail: stacy.oblenes@iwk.nshealth.ca).

0022-5223/\$36.00

Copyright (c) 2013 by The American Association for Thoracic Surgery http://dx.doi.org/10.1016/j.jtcvs.2013.05.032
$\mathrm{Ca}^{2+}$, and contains lidocaine (Table 1). Del Nido cardioplegia usually is given as a single dose, ${ }^{9-11}$ whereas our standard cardioplegia is given as an induction dose followed by maintenance doses approximately every 20 minutes. The del Nido cardioplegia strategy results in lower postoperative troponin release in pediatric patients compared with our standard cardioplegia. ${ }^{9}$

Because elderly myocardium is similar to immature myocardium in that both are particularly susceptible to reperfusion injury related to $\mathrm{Ca}^{2+}$ overload, ${ }^{3-8,12-14}$ we hypothesized that a del Nido cardioplegia strategy also may be beneficial in the elderly. We previously showed, in cardiomyocytes from aged rats $(\approx 24 \mathrm{mo})$, that arrest with del Nido cardioplegia results in less activity during the ischemic period, lower diastolic $\mathrm{Ca}^{2+}$ during ischemia and reperfusion, and avoidance of $\mathrm{Ca}^{2+}$-induced hypercontraction during early reperfusion. ${ }^{15}$ The objective of this study was to determine if the beneficial effects seen with del Nido cardioplegia in aged cardiomyocytes translate into improved functional recovery in elderly whole hearts.

Sodium influx is thought to be the main cause of intracellular $\mathrm{Ca}^{2+}$ accumulation during ischemia by driving reverse-mode $\mathrm{Na}^{+} / \mathrm{Ca}^{2+}$ exchange. ${ }^{16,17}$ During hyperkalemic cardioplegic arrest, membrane depolarization opens a proportion of the voltage-gated $\mathrm{Na}^{+}$channels 


\section{Abbreviation and Acronym \\ $\mathrm{I}_{\mathrm{Na}}=$ sodium current}

spanning the cell membrane. Most of these channels are inactivated rapidly, thereby preventing action potential generation and propagation, but a small fraction remain tonically available and allow $\mathrm{Na}^{+}$to flow into the cell via a window current. ${ }^{18-20}$ Lidocaine used as an additive to depolarizing cardioplegia may limit $\mathrm{Na}^{+}$influx by blocking the window current, however, this has not been well described. We investigated whether the concentration of lidocaine present in del Nido cardioplegia is adequate to minimize the potential for $\mathrm{Na}^{+}$influx via the window current.

\section{MATERIALS AND METHODS}

\section{Experimental Animals and Anesthesia}

Experiments were performed in accordance with guidelines published by the Canadian Council on Animal Care. ${ }^{21}$ Male Fisher 344 rats (3-4 mo for isolated cardiomyocyte studies, and 23-24 mo for isolated heart studies) obtained from Charles River Laboratories (Saint-Constant, Canada) were heparinized (intraperitoneally, $3000 \mathrm{U} / \mathrm{kg}$; Pharmaceutical Partners of Canada, Richmond, Ontario, Canada), and anesthetized with sodium pentobarbital (intraperitoneally, $160 \mathrm{mg} / \mathrm{kg}$; Veterinary Medication Distribution Centre; Saint-Hyacinthe, Quebec, Canada). Hearts were removed rapidly and placed in ice-cold Tyrode's solution for isolated cardiomyocyte studies $\left(\mathrm{NaCl} 140 \mathrm{mmol} / \mathrm{L}, \mathrm{KCl} 5.4 \mathrm{mmol} / \mathrm{L}, \mathrm{Na}_{2} \mathrm{HPO}_{4} 1\right.$ $\mathrm{mmol} / \mathrm{L}, \mathrm{CaCl}_{2} 1 \mathrm{mmol} / \mathrm{L}, \mathrm{MgCl}_{2} 1 \mathrm{mmol} / \mathrm{L}$, glucose $10 \mathrm{mmol} / \mathrm{L}$, HEPES $5 \mathrm{mmol} / \mathrm{L}, \mathrm{pH}$ 7.4), or Krebs-Henseleit buffer for isolated heart studies $\left(\mathrm{NaCl} 118 \mathrm{mmol} / \mathrm{L}, \mathrm{KCl} 4.71 \mathrm{mmol} / \mathrm{L}, \mathrm{NaHCO}_{3} 25.0 \mathrm{mmol} / \mathrm{L}, \mathrm{KH}_{2} \mathrm{PO}_{4}\right.$ $1.20 \mathrm{mmol} / \mathrm{L}, \mathrm{CaCl}_{2} 2.50 \mathrm{mmol} / \mathrm{L}, \mathrm{MgSO}_{4} 1.20 \mathrm{mmol} / \mathrm{L}$, glucose 11 $\mathrm{mmol} / \mathrm{L}$, ethylenediaminetetraacetic acid $0.5 \mathrm{mmol} / \mathrm{L}$, equilibrated with $95 \% \mathrm{O}_{2} / 5 \% \mathrm{CO}_{2}, \mathrm{pH} 7.4$ ).

\section{Cardiac Myocyte Isolation}

Ventricular cardiomyocytes were obtained by enzymatic dissociation. Hearts cannulated via the aorta were perfused with Tyrode's solution $\left(37^{\circ} \mathrm{C}, 5 \mathrm{~min}\right)$, followed by 10 minutes with $\mathrm{Ca}^{2+}$ free Tyrode's, then Tyrode's containing collagenase type II $(73.7 \mathrm{U} / \mathrm{mL}$; Worthington Biochemical Corp, Lakewood, NJ), taurine (20 mmol/L), $\mathrm{CaCl}_{2}(30$ $\mu \mathrm{mol} / \mathrm{L})$, and bovine serum albumin $(0.1 \%)$. The right ventricle was dissected off and manually triturated to separate individual cardiomyocytes, which were stored in Kraft-Brühe solution (K-glutamate 100 $\mathrm{mmol} / \mathrm{L}, \mathrm{K}$-aspartate $10 \mathrm{mmol} / \mathrm{L}, \mathrm{KCl} 2.5 \mathrm{mmol} / \mathrm{L}, \mathrm{KH}_{2} \mathrm{PO}_{4} 10 \mathrm{mmol} / \mathrm{L}$, $\mathrm{MgSO}_{4} 2 \mathrm{mmol} / \mathrm{L}$, glucose $20 \mathrm{mmol} / \mathrm{L}$, taurine $20 \mathrm{mmol} / \mathrm{L}$, creatine 5 $\mathrm{mmol} / \mathrm{L}$, ethylene glycol tetraacetic acid $0.5 \mathrm{mmol} / \mathrm{L}$, HEPES $5 \mathrm{mmol} / \mathrm{L}$, bovine serum albumin $0.1 \%, \mathrm{pH} 7.2$ ). Only quiescent rod-shaped myocytes with clear striations were selected for these studies.

\section{Electrophysiological Solutions and Protocols}

The sodium current $\left(\mathrm{I}_{\mathrm{Na}}\right)$ was recorded in single cardiomyocytes using the whole-cell patch-clamp technique with reduced extracellular $\mathrm{Na}^{+}$ concentrations to facilitate voltage clamping. Myocytes were superfused with modified Tyrode's $(\mathrm{NaCl} 12 \mathrm{mmol} / \mathrm{L}, \mathrm{CsCl} 130 \mathrm{mmol} / \mathrm{L}, \mathrm{TEA}-\mathrm{Cl}$ $5.4 \mathrm{mmol} / \mathrm{L}, \mathrm{CaCl}_{2} 1 \mathrm{mmol} / \mathrm{L}, \mathrm{MgCl}_{2} 1 \mathrm{mmol} / \mathrm{L}, \mathrm{HEPES} 10 \mathrm{mmol} / \mathrm{L}$, glucose $\left.5 \mathrm{mmol} / \mathrm{L}, \mathrm{pH} 7.4,22^{\circ} \mathrm{C}-23^{\circ} \mathrm{C}\right)$ including $\mathrm{NiCl}_{2}(40 \mu \mathrm{mol} / \mathrm{L})$ and nitrendipine $(10 \mu \mathrm{mol} / \mathrm{L})$ to block $\mathrm{Ca}^{2+}$ currents. The pipette solution contained $\mathrm{CsCl} 135 \mathrm{mmol} / \mathrm{L}, \mathrm{CaCl}_{2} 0.1 \mathrm{mmol} / \mathrm{L}, \mathrm{MgCl}_{2} 1 \mathrm{mmol} / \mathrm{L}$, $\mathrm{NaCl} 5 \mathrm{mmol} / \mathrm{L}$, ethylene glycol tetraacetic acid $10 \mathrm{mmol} / \mathrm{L}$,
Mg-adenosine triphosphate $4 \mathrm{mmol} / \mathrm{L}$, Na-phosphocreatine $6.6 \mathrm{mmol} / \mathrm{L}$, Na-guanosine triphosphate $0.3 \mathrm{mmol} / \mathrm{L}$, and HEPES $10 \mathrm{mmol} / \mathrm{L}$, $\mathrm{pH} 7.2$. The resistance of the borosilicate glass micropipettes $(1.5 \mathrm{~mm}$ outer diameter, $0.75 \mathrm{~mm}$ inner diameter) was 3 to $5 \mathrm{M} \Omega$, seal resistance was 2 to $15 \mathrm{G} \Omega$, and rupturing the sarcolemma in the patch for voltage clamp experiments resulted in access resistances of 5 to $15 \mathrm{M} \Omega$. Series resistance compensation averaged $80 \%$ to $85 \%$ using an Axopatch 200B amplifier (Molecular Devices, Sunnyvale, Calif). Data were digitized using a Digidata 1440 and pCLAMP 10 software (Molecular Devices).

The voltage clamp protocol for measuring $\mathrm{I}_{\mathrm{Na}}$ current-voltage relationships and activation kinetics consisted of holding myocytes at $-100 \mathrm{mV}$ and then giving a series of $20-\mathrm{ms}, 10-\mathrm{mV}$ steps from -80 to $+60 \mathrm{mv}$. $\mathrm{I}_{\mathrm{Na}}$ activation kinetics were determined by calculating chord conductance (G) using the following equation: $G=I /\left(V_{m}-E_{\text {rev }}\right)$, where $V_{m}$ represents the depolarizing voltages and $\mathrm{E}_{\mathrm{rev}}$ is the reversal potential estimated from the current-voltage relation of $\mathrm{I}_{\mathrm{Na}}$. The protocol for measuring $\mathrm{I}_{\mathrm{Na}}$ inactivation consisted of holding myocytes at $-140 \mathrm{mV}$ and giving a series of 500-ms voltage-clamp conditioning steps from $-120 \mathrm{mV}$ to $-20 \mathrm{mV}$ followed by a $20-\mathrm{ms}$ voltage clamp test step to $-20 \mathrm{mV}$. Activation and inactivation curves were generated by fitting normalized data with a Boltzmann function to determine the $\mathrm{V}_{1 / 2}$ of activation $\left(\mathrm{V}_{1 / 2[\text { act] }}\right)$, and inactivation $\left(\mathrm{V}_{1 / 2[\text { inact] }}\right)$ in the presence and absence (control) of lidocaine $0.36 \mathrm{mmol} / \mathrm{L}$, as found in del Nido cardioplegia.

\section{Isolated Working Heart}

Hearts were cannulated via the aorta and pulmonary vein on a working heart apparatus (Radnoti, Inc, Monrovia, Calif), and perfused retrograde with Krebs-Henseleit buffer at $10 \mathrm{~mL} / \mathrm{min}\left(37^{\circ} \mathrm{C}\right)$. A temperature probe and electrocardiogram electrode were placed through the pulmonary artery into the right ventricular outflow tract. Left atrial and aortic pressure and aortic flow (Transonic Systems, Inc, Ithaca, NY) were monitored continually using a PowerLab data acquisition system (ADI Instruments, Colorado Springs, Colo). Coronary flow was measured by timed collection of effluent. After a 5-minute stabilization period, hearts were switched to constant pressure mode $\left(100 \mathrm{~cm} \mathrm{H}_{2} \mathrm{O}\right)$ for 5 minutes, and then into working heart mode for 5 minutes (preload, $20 \mathrm{~cm} \mathrm{H}_{2} \mathrm{O}$; afterload, $100 \mathrm{~cm} \mathrm{H}_{2} \mathrm{O}$ ). Only hearts that met the following predetermined baseline criteria were used in this study: heart rate greater than $200 \mathrm{bpm}$, regular rhythm, cardiac output greater than $25 \mathrm{~mL} / \mathrm{min}$, and coronary flow greater than $10 \mathrm{~mL} /$ min. ${ }^{22}$ After the baseline working heart period, hearts were arrested with cardioplegia as described later, and then exposed to ambient room temperature $\left(22^{\circ} \mathrm{C}-23^{\circ} \mathrm{C}\right)$ for a 60 -minute ischemic period. Reperfusion began with retrograde perfusion at $4 \mathrm{~mL} / \mathrm{min}$ and increased in $0.5-\mathrm{mL} / \mathrm{min}$ increments every 30 seconds to $10 \mathrm{~mL} / \mathrm{min}$. Coronary effluent then was collected and frozen $\left(-80^{\circ} \mathrm{C}\right)$ for later determination of troponin concentration (2010-2-HS, rat serum cardiac troponin-I enzyme-linked immunosorbent assay; Life Diagnostics, Inc). After a total of 15 minutes, hearts were switched to constant pressure mode for an additional 5 minutes and then into working heart mode for 60 minutes. At the end of the protocol, the ventricles were blotted dry, weighed, then desiccated at $80^{\circ} \mathrm{C}$ for 24 hours and re-weighed. All flow values were indexed to dry weight of the ventricles.

\section{Cardioplegia Preparation and Delivery}

Autologous blood was collected from the chest cavity using a syringe containing heparin $(200 \mathrm{U})$ as the hearts were being harvested. Cardioplegia solutions were prepared according to our clinical protocols (Table 1), cooled in an ice bath, and oxygenated. Before delivery, the cardioplegia was filtered using a $20-\mu \mathrm{m}$ pore size vacuum filter (EMD Millipore, Billerica, Md). The cardioplegia temperature was $1.9^{\circ} \mathrm{C} \pm 0.4^{\circ} \mathrm{C}$.

The cardioplegia strategies used in this study were modeled after those we use in the clinic. ${ }^{9}$ Standard cardioplegia was delivered as an induction dose $(15 \mathrm{~mL} / \mathrm{kg})$ followed by additional doses $(5 \mathrm{~mL} / \mathrm{kg})$ every 20 minutes 
TABLE 1. Composition of cardioplegia solutions

\begin{tabular}{lcc}
\hline & $\begin{array}{c}\text { Standard } \\
\text { cardioplegia }\end{array}$ & $\begin{array}{c}\text { del Nido } \\
\text { cardioplegia }\end{array}$ \\
\hline Base solution (1 L) & D5 $0.225 \%$ NaCl & Plasmalyte A (ref) \\
Components (mmol/L) & 38.8 & 140 \\
$\quad \mathrm{Na}$ & 38.8 & 98 \\
$\mathrm{Cl}$ & & 5 \\
$\mathrm{~K}$ & & 1.5 \\
Mg & & 27 \\
Acetate & 278 & 23 \\
Gluconate & & \\
Glucose & 44 & 13 \\
Additives (mL/L base solution) & 100 & 13 \\
KCl 2 mEq/mL & 15 & 10 \\
NaHCO3 1 mEq/mL & - & 13 \\
MgSO4 0.2 g/mL & - & 13 \\
Lidocaine 1\% & $4: 1$ & $1: 4$ \\
Mannitol 25\% & & \\
Dilution (blood:cardioplegia) & & 24 \\
Estimated final composition & 18 & 7 \\
$\quad$ (mmol/L) & 5 & 0.24 \\
K & 1.0 & 0.375 \\
Mg & 51 & \\
Ca & - & \\
Glucose & & \\
Lidocaine & & \\
Estimated final osmolarity & & \\
Estimated final hematocrit (\%) & & \\
\hline & & \\
\hline
\end{tabular}

(total, $25 \mathrm{~mL} / \mathrm{kg}$ ). Del Nido cardioplegia was delivered as a single induction dose $(15 \mathrm{~mL} / \mathrm{kg})$ with no additional doses during the 60 -minute ischemic period. The cardioplegia was delivered by hand injection at pressures of $50 \mathrm{~mm} \mathrm{Hg}$ or less.

\section{Statistical Analysis}

Data are presented as mean \pm SEM. Tests for statistical significance included the following: paired $t$ test, unpaired $t$ test, the Fisher exact test, and mixed linear model analysis followed by the Tukey-Kramer test where appropriate.

\section{RESULTS}

The Lidocaine Concentration Used in del Nido Cardioplegia Minimizes the Potential for $\mathrm{Na}^{+}$ Window Current During Cardioplegic Arrest

To determine if the lidocaine concentration in del Nido cardioplegia is adequate to minimize the potential for $\mathrm{Na}^{+}$influx via the window current, $\mathrm{Na}^{+}$channel activation and inactivation curves were examined in the presence and absence of lidocaine $0.36 \mathrm{mmol} / \mathrm{L}$ (Figure 1). Lidocaine shifted the inactivation curve to the left $\left(\mathrm{V}_{1 / 2[\text { inact }]}-101.2 \pm 0.7\right.$ vs $-88.9 \pm 0.3 \mathrm{mV}$; $P=.00019 ; \mathrm{n}=8$ ), with no change in slope factor, indicating lower $\mathrm{Na}^{+}$channel availability at any given membrane potential. Furthermore, the activation curve was shifted to the right $\left(\mathrm{V}_{1 / 2 \text { [act] }}-47.7 \pm 0.7 \mathrm{vs}-56.7 \pm\right.$
$0.4 \mathrm{mV} ; P<.001 ; \mathrm{n}=8$ ), indicating that opening of available channels is reduced with lidocaine at any given membrane potential. The result of this shift in the activation and inactivation curves away from each other is that the $\mathrm{Na}^{+}$window current, represented by the area under the 2 curves, is minimized with lidocaine $0.36 \mathrm{mmol} / \mathrm{L}$ (Figure 1, B).

\section{Del Nido Cardioplegia Reduces the Incidence of Spontaneous Activity During Cardioplegic Arrest, and Delays Return of Activity During Reperfusion}

To determine the relative ability of del Nido cardioplegia to protect aged hearts, we studied senescent rats using our working heart model of arrest with blood cardioplegia. Sixteen of 20 hearts $(80 \%)$ met the predetermined functional criteria for inclusion in the study. Eight hearts were arrested with standard cardioplegia and 8 were arrested with del Nido cardioplegia. Cardiac temperature was $21^{\circ} \mathrm{C} \pm 1{ }^{\circ} \mathrm{C}$ in each group after induction and essentially was unchanged immediately before reperfusion $\left(20^{\circ} \mathrm{C} \pm 1^{\circ} \mathrm{C}\right.$ in each group).

Spontaneous electromechanical activity was observed during the arrest period in 7 of 8 hearts in the standard cardioplegia group (Figure 2). This was in the form of occasional wide complex beats seen on the electrocardiogram (Figure 2, $A$ ) with accompanying mechanical activity. In contrast, spontaneous activity was seen in only 1 of 8 hearts arrested with del Nido cardioplegia (Figure 2, $B$; $P=.01$ ).

After the start of reperfusion, all hearts had spontaneous return of rhythm. However, the time to return of the first heartbeat was twice as long in the del Nido group when compared with the standard cardioplegia group (Figure 2, $C$ and $D ; 67 \pm 6$ vs $32 \pm 5$ s; $P=.0007)$. All hearts had occasional extra systoles or short runs of bigeminy during the reperfusion period. Four hearts in the standard cardioplegia group and 1 heart in the del Nido group $(P=$ not specified $[\mathrm{NS}])$ had short runs of sustained tachyarrhythmia that resolved spontaneously. One heart in the del Nido group had a short period of asystole, which was not seen in any of the hearts protected with standard cardioplegia.

\section{Use of del Nido Cardioplegia Results in Less Myocardial Damage and Lower Coronary Vascular Resistance During Reperfusion}

To assess the impact of del Nido cardioplegia on cardiomyocyte damage after arrest and reperfusion, we assayed troponin I in the coronary effluent. Troponin levels were approximately $70 \%$ less in hearts protected with del Nido cardioplegia when compared with standard cardioplegia $(0.24 \pm 0.05$ vs $0.89 \pm 0.23 \mathrm{ng} / \mathrm{mL}$; $P=.02)$. We examined coronary vascular resistance during the retrograde perfusion phase of reperfusion and found that 


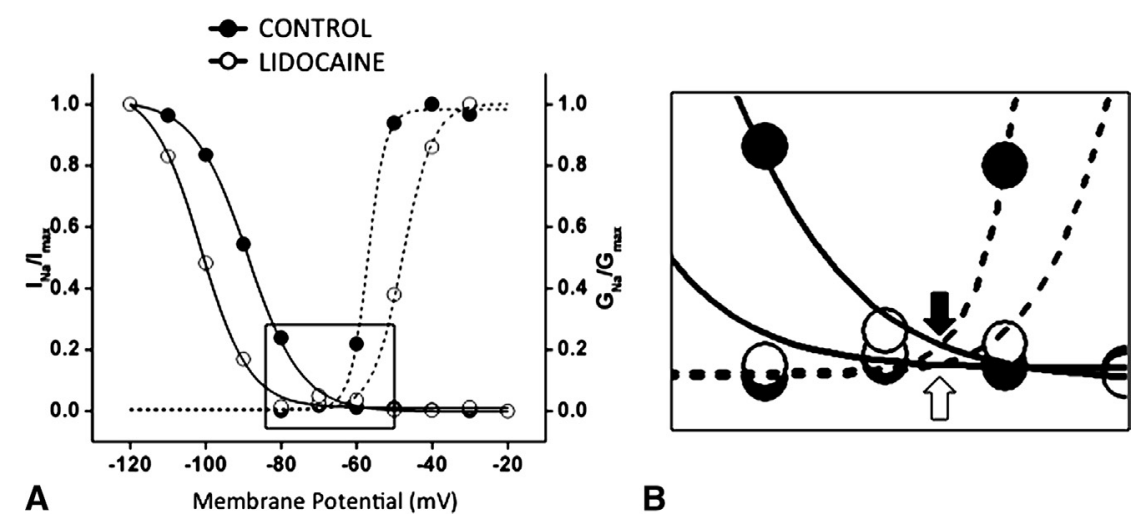

FIGURE 1. Analysis of lidocaine impact on $\mathrm{Na}^{+}$channel activation and inactivation kinetics. A, Activation (dashed line) and inactivation (solid line) curves were generated in the presence and absence (control) of lidocaine $0.36 \mathrm{mmol} / \mathrm{L}$ as found in del Nido cardioplegia. Lidocaine shifts the activation curve to the right and the inactivation curve to the left. B, Magnified view of the area highlighted in panel A. The area under the intersection of the control activation and inactivation curves (solid arrow) represents the $\mathrm{Na}^{+}$window current. This is minimized in the presence of lidocaine (open arrow).

it was approximately $50 \%$ less in hearts arrested with del Nido cardioplegia $(0.75 \pm 0.05$ vs $1.43 \pm 0.31 \mathrm{~mm}$ $\left.\mathrm{Hg} \cdot \min \cdot \mathrm{mL}^{-1} \cdot \mathrm{g}^{-1} ; P=.0497\right)$. This was caused by an increase in resistance over baseline in the standard cardioplegia group, which was not seen in the del Nido cardioplegia group ( $\Delta$ coronary vascular resistance $0.68 \pm$ $\left.0.22 \mathrm{vs}-0.05 \pm 0.04 \mathrm{~mm} \mathrm{Hg} \cdot \min \cdot \mathrm{mL}^{-1} \cdot \mathrm{g}^{-1} ; P=.007\right)$.

\section{Del Nido Cardioplegia Is Associated With Superior Functional Recovery After Cardioplegic Arrest}

To evaluate the impact of del Nido cardioplegia on functional recovery, the hearts were switched into working mode for 60 minutes after the 20-minute reperfusion period, and hemodynamic parameters were examined at fixed filling pressure (20 $\mathrm{cm} \mathrm{H}_{2} \mathrm{O}$, Table 2, Figure 3). All hearts
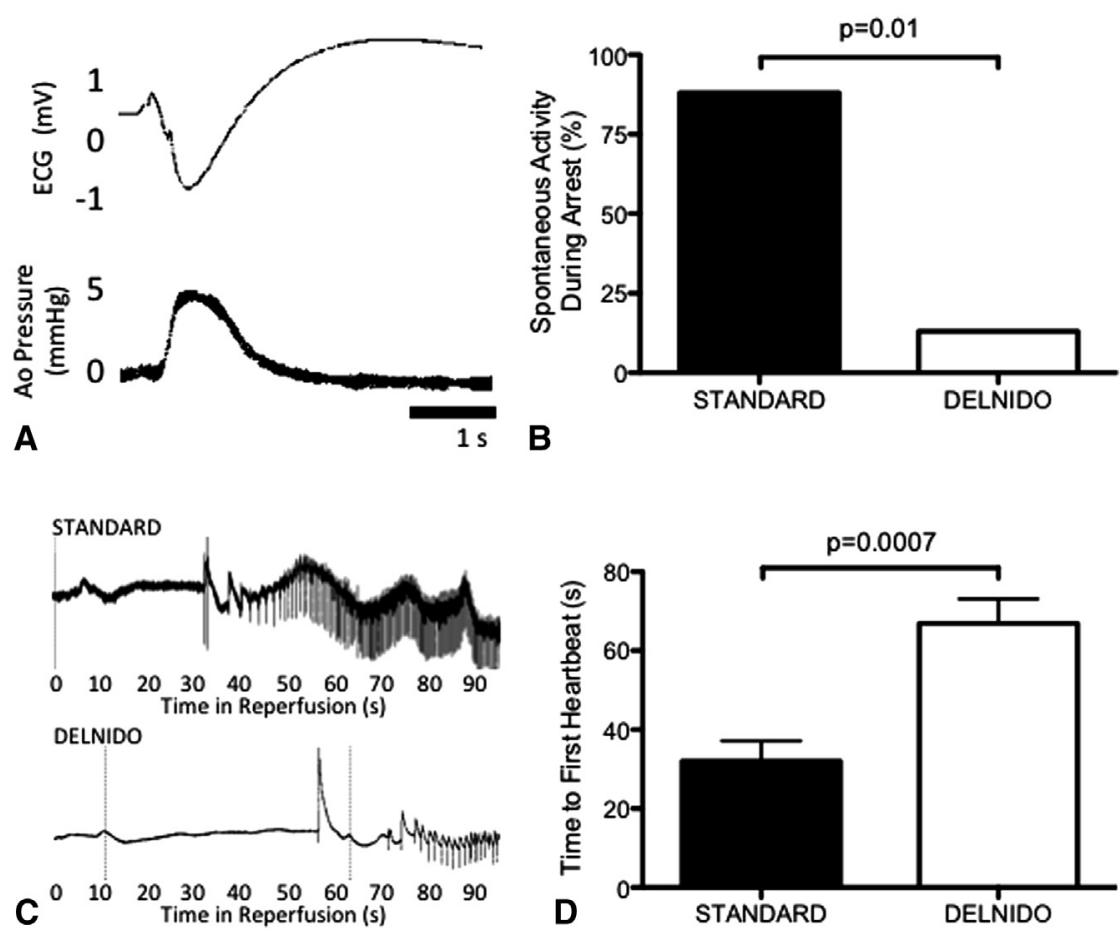

FIGURE 2. Analysis of spontaneous activity during cardioplegic arrest and return of first heart beat after reperfusion. A, Representative tracings of spontaneous ECG activity (upper panel), and Ao pressure fluctuation (lower panel) in a heart arrested with standard cardioplegia. B, Bar graph representing the percentage of hearts showing spontaneous activity during arrest with either standard or del Nido cardioplegia. C, Representative ECG tracings from the start of reperfusion in hearts arrested with standard (upper panel) and del Nido cardioplegia (lower panel). D, Bar graph representing the average time to return of the first heart beat after reperfusion in hearts arrested with standard and del Nido cardioplegia. Bars represent the mean \pm SEM ( $\mathrm{n}=8$ hearts per group). Ao, Aortic; ECG, electrocardiogram. 
TABLE 2. Hemodynamic parameters measured during working heart mode

\begin{tabular}{|c|c|c|c|c|c|c|c|}
\hline \multirow[b]{2}{*}{ Parameter } & \multirow[b]{2}{*}{ Baseline } & \multicolumn{6}{|c|}{ After reperfusion (min) } \\
\hline & & 5 & 10 & 15 & 30 & 45 & 60 \\
\hline \multicolumn{8}{|l|}{ Heart rate (bpm) } \\
\hline Standard & $224 \pm 6$ & $197 \pm 16$ & $200 \pm 16$ & $200 \pm 16$ & $204 \pm 19$ & $198 \pm 21$ & $198 \pm 22$ \\
\hline del Nido & $219 \pm 6$ & $228 \pm 8$ & $231 \pm 9$ & $235 \pm 6$ & $233 \pm 9$ & $233 \pm 11$ & $229 \pm 12$ \\
\hline$P$ & NS & NS & NS & NS & NS & NS & NS \\
\hline \multicolumn{8}{|l|}{ Systolic pressure $(\mathrm{mm} \mathrm{Hg})$} \\
\hline Standard & $133 \pm 5$ & $99 \pm 6$ & $99 \pm 6$ & $99 \pm 7$ & $93 \pm 9$ & $98 \pm 9$ & $97 \pm 8$ \\
\hline del Nido & $138 \pm 4$ & $128 \pm 4$ & $127 \pm 5$ & $128 \pm 4$ & $127 \pm 4$ & $125 \pm 5$ & $123 \pm 4$ \\
\hline$P$ & .5 & .0006 & .0008 & .0006 & .0001 & .0011 & .0018 \\
\hline \multicolumn{8}{|c|}{ Rate pressure product $\left(\times 10^{2} \mathrm{~mm} \mathrm{Hg} \cdot \min ^{-1}\right)$} \\
\hline Standard & $30 \pm 1$ & $20 \pm 2$ & $20 \pm 2$ & $20 \pm 2$ & $19 \pm 3$ & $20 \pm 3$ & $20 \pm 3$ \\
\hline del Nido & $30 \pm 1$ & $29 \pm 1$ & $29 \pm 1$ & $30 \pm 1$ & $29 \pm 1$ & $29 \pm 1$ & $28 \pm 1$ \\
\hline$P$ & .8 & .0005 & .0006 & .0002 & .0002 & .0006 & .0017 \\
\hline \multicolumn{8}{|c|}{ Cardiac output $\left(\mathrm{mL} \cdot \min ^{-1} \cdot \mathrm{g}^{-1}\right)$} \\
\hline Standard & $181 \pm 18$ & $85 \pm 23$ & $87 \pm 23$ & $88 \pm 24$ & $86 \pm 24$ & $92 \pm 23$ & $86 \pm 22$ \\
\hline del Nido & $196 \pm 9$ & $177 \pm 14$ & $180 \pm 16$ & $181 \pm 15$ & $177 \pm 14$ & $174 \pm 13$ & $173 \pm 14$ \\
\hline$P$ & 6 & .0007 & .0006 & .0007 & .0009 & .0017 & .0008 \\
\hline \multicolumn{8}{|c|}{ Stroke volume $\left(\times 10^{-2} \mathrm{~mL} \cdot \mathrm{g}^{-1}\right)$} \\
\hline Standard & $81 \pm 7$ & $40 \pm 10$ & $41 \pm 10$ & $41 \pm 10$ & $40 \pm 10$ & $43 \pm 10$ & $40 \pm 10$ \\
\hline del Nido & $90 \pm 4$ & $78 \pm 6$ & $78 \pm 6$ & $77 \pm 5$ & $76 \pm 5$ & $75 \pm 5$ & $76 \pm 4$ \\
\hline$P$ & .4 & .0009 & .0009 & .0013 & .0016 & .0026 & .0008 \\
\hline \multicolumn{8}{|c|}{ Coronary flow $\left(\mathrm{mL} \cdot \mathrm{min}^{-1} \cdot \mathrm{g}^{-1}\right)$} \\
\hline Standard & $97 \pm 5$ & $61 \pm 9$ & $60 \pm 9$ & $61 \pm 7$ & $60 \pm 11$ & $65 \pm 11$ & $61 \pm 12$ \\
\hline del Nido & $103 \pm 7$ & $101 \pm 6$ & $101 \pm 6$ & $101 \pm 6$ & $101 \pm 6$ & $99 \pm 6$ & $101 \pm 9$ \\
\hline$P$ & 6 & .0009 & .0008 & .001 & .0007 & .0014 & .0003 \\
\hline
\end{tabular}

Mixed linear model analysis was not significant so post hoc comparisons were not performed $(\mathrm{n}=8$ per group up to the 30 -minute time point, and $\mathrm{n}=7$ for the 45 - and 60 -minute time points). NS, Not significant.

completed the entire protocol with the exception of 1 in each group in which air was entrained near the end of the studies and therefore did not contribute data for the final 2 time points. Hemodynamic parameters were not significantly different during baseline working heart mode in hearts arrested with either standard or del Nido cardioplegia (Table 2, Figure 3). After reperfusion, hearts protected with del Nido cardioplegia had higher peak systolic pressure, left ventricular developed pressure, and rate pressure product (Table 2, Figure 3). Cardiac output was higher throughout the working heart period in hearts arrested with del Nido cardioplegia as was stroke volume and stroke work (Table 2, Figure 3).

\section{Myocardial Edema Is Not Affected by Cardioplegia Strategy}

To assess the potential impact of cardioplegia strategy on the development of myocardial edema, we examined the water content in the ventricular myocardium at the end of each study. The amount of myocardial water was similar in each group $(0.94 \pm 0.05$ vs $0.92 \pm 0.02 \mathrm{~g}$ for standard and del Nido cardioplegia, respectively; $P=\mathrm{NS}$ ). Similarly, the ratio of water to dry weight of the ventricular myocardium was not different $(5.1 \pm 0.1$ vs $4.9 \pm 0.1$ for standard and del Nido cardioplegia, respectively; $P=\mathrm{NS}$ ).

\section{DISCUSSION}

Aged myocardium behaves differently than mature myocardium during ischemia and is not as well protected by some cardioplegia solutions. ${ }^{23,24}$ This may be one reason why older patients undergoing cardiac surgery have impaired recovery of ventricular function and lower survival when compared with younger adult patients. ${ }^{1,2}$ The mechanism responsible for the intolerance to ischemia appears to be related to accelerated accumulation of intracellular $\mathrm{Ca}^{2+} \cdot{ }^{5-8}$ Strategies to limit the accumulation of intracellular $\mathrm{Ca}^{2+}$ in aged hearts improve the recovery of ventricular function after ischemia. ${ }^{7,8}$ In previous studies, ${ }^{15}$ we observed that del Nido cardioplegia, developed for the protection of immature myocardium, potentially has beneficial effects in cardiomyocytes from aged rats. The results of our current study comparing a del Nido cardioplegia strategy with a standard multidose 4:1 blood cardioplegia strategy suggest that those benefits translate into reduced myocardial damage and improved functional recovery in the whole aged heart. The rats used for these isolated heart studies were 23 to 24 months of age. Survival to this age in this strain of rats is approximately $50 \%,{ }^{25}$ which corresponds to a human age of older than 70 years (World Health Organization mortality statistics, 2013). 

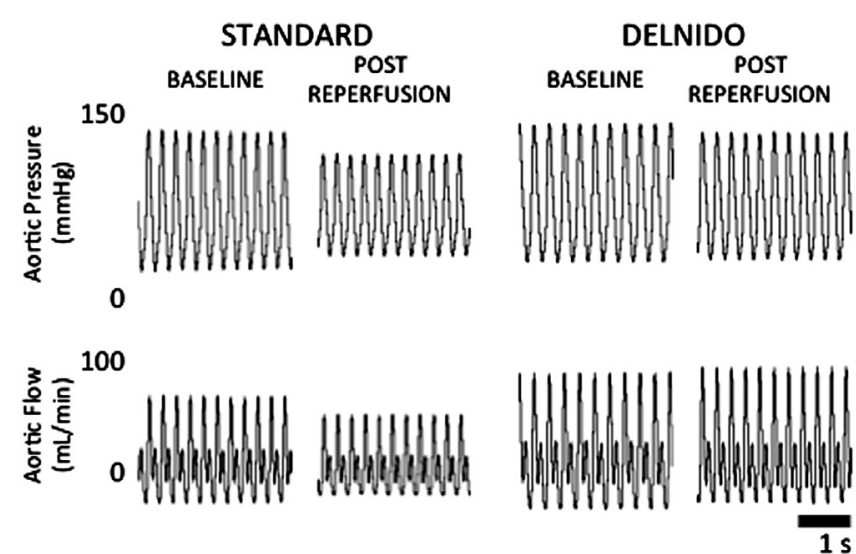

A
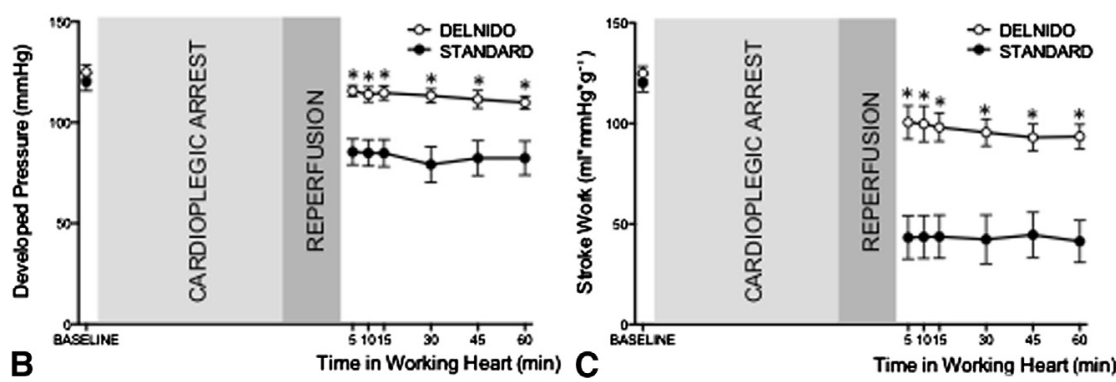

FIGURE 3. Analysis of cardiac function before and after arrest and reperfusion. A, Representative tracings of aortic pressure (upper panels) and aortic flow (lower panels) recorded in working heart mode. Baseline and postreperfusion tracings are shown from hearts arrested with standard (left panels) and del Nido cardioplegia (right panels). B, Graph showing left ventricular developed pressure measured during working heart mode before (baseline) and at several time points after 60 minutes of cardioplegic arrest and 20 minutes of reperfusion for the standard and del Nido cardioplegia groups. C, Graph showing stroke work indexed to dry heart weight measured during working heart mode before and after cardioplegic arrest. Data points represent the mean \pm SEM ( $\mathrm{n}=8$ per group up to the 30 -minute time point and 7 per group for the 45 - and 60 -minute time points). $* P \leq .001$.

Lidocaine, which is found in del Nido cardioplegia, is a common additive but the mechanism of benefit is not clearly understood. Possibilities include coronary vasodilation to improve cardioplegia delivery, prevention of reperfusion arrhythmias, and reduction of $\mathrm{Na}^{+}$influx via the window current during arrest. During cardioplegic arrest, membrane potential stabilizes at a relatively depolarized level at which a small tonic inward $\mathrm{Na}^{+}$current is active. This window current is related to a small proportion of the voltage gated $\mathrm{Na}^{+}$channels that are available, open, and in the active state. ${ }^{18-20}$ This is one potential drawback of depolarizing cardioplegic arrest because $\mathrm{Na}^{+}$influx is thought to be the prime driver of $\mathrm{Ca}^{2+}$ overload. ${ }^{16,17}$ With a view to potential optimization of the del Nido cardioplegia formulation, we confirmed that lidocaine shifts the activation and inactivation curves for $\mathrm{Na}^{+}$channels in a way that minimizes the potential for $\mathrm{Na}^{+}$window current. This may represent an important mechanism of benefit with del Nido cardioplegia, and the lidocaine concentration in the current formulation appears sufficient.

Analogous to the observations in our previous isolated cardiomyocyte study, ${ }^{15}$ we found a reduction in spontaneous activity in hearts arrested with del Nido cardioplegia.
This may be related to $\mathrm{Na}^{+}$channel blockade with lidocaine, but del Nido cardioplegia also contains slightly more potassium and magnesium than our standard cardioplegia, resulting in more pronounced membrane depolarization ${ }^{9}$ that also may contribute to more effective arrest. Reduced spontaneous activity during the ischemic period should limit the development of intracellular acidosis, which drives the $\mathrm{Na}^{+}$, and subsequently $\mathrm{Ca}^{2+}$, influx that contributes to ischemia-reperfusion injury.

The time to the return of the first heartbeat was twice as long with del Nido cardioplegia. This corresponds with what we observed anecdotally in our clinical practice when we switched from standard to del Nido cardioplegia for our pediatric patients. This may represent a residual effect of lidocaine but it is not clear if the delayed resumption of rhythm plays any role in the benefit seen with del Nido cardioplegia. It is possible that a period of persistent inactivity during early reperfusion may improve myocardial recovery in a manner similar to that seen with the use of warm terminal cardioplegia. ${ }^{26}$

During ischemia and reperfusion, the late or persistent inward $\mathrm{Na}^{+}$current is increased, ${ }^{27,28}$ which can predispose to early after potentials and arrhythmia. ${ }^{27}$ This 
late $\mathrm{Na}^{+}$current can be reduced by $\mathrm{Na}^{+}$channel blockers including lidocaine. ${ }^{28}$ In our study we saw no episodes of ventricular fibrillation and only a few runs of tachycardia that were short and self-limiting. We did not see a significant reduction with del Nido cardioplegia, but we cannot exclude the possibility that this might become apparent in a larger study.

Coronary resistance during reperfusion was increased in the standard cardioplegia group but not in the del Nido cardioplegia group. This also may be related to the presence of lidocaine in del Nido cardioplegia, which can promote coronary arteriolar vasodilation. ${ }^{29}$ However, there are alternative explanations including the possibility of increased microvascular obstruction related to hypothermia-induced sludging, ${ }^{30}$ with the higher hematocrit level in the $4: 1$ standard cardioplegia.

In the adult, blood cardioplegia appears to offer superior myocardial protection when compared with crystalloid cardioplegia. ${ }^{31,32}$ However, the optimal dilution of the cardioplegia solution is the subject of ongoing debate. Although the benefits of blood cardioplegia are apparent with minimal hematocrit level, ${ }^{32}$ it has been suggested that concentrated blood cardioplegia improves recovery by limiting the development of myocardial edema. We did not see any difference in myocardial edema in this study comparing del Nido (1:4 blood:crystalloid) and standard cardioplegia (4:1). This may be because, despite different dilutions, the estimated final oncotic pressure is similar in both solutions (Table 1). Potential advantages of dilute cardioplegia include reduced viscosity that may enhance cardioplegia delivery, ${ }^{33}$ and reduced potential for sludging and microvascular obstruction with hypothermia. ${ }^{30}$ Furthermore, all the $\mathrm{Ca}^{2+}$ in these cardioplegia solutions comes from the blood component, so del Nido has a lower $\mathrm{Ca}^{2+}$ concentration, which may be beneficial, particularly in elderly hearts in which strategies to limit $\mathrm{Ca}^{2+}$ influx can reduce ischemia-reperfusion injury. ${ }^{7,8}$

This study was a comparison of 2 cardioplegia strategies that currently are used clinically, ${ }^{9-11}$ therefore del Nido cardioplegia was administered as a single dose and standard cardioplegia was delivered in multiple doses. Evidence suggests that, in adults, multidose 4:1 blood cardioplegia offers benefits over a single dose (reviewed by Buckberg $^{34}$ ), and is the strategy we currently use clinically. In contrast, del Nido cardioplegia, which typically is used as a single dose, or is re-dosed at long intervals, ${ }^{9-11}$ compares favorably with multidose $4: 1$ cardioplegia. ${ }^{9}$ However, this is primarily in pediatric patients in whom there is some evidence that re-dosing of cardioplegia is detrimental. ${ }^{35}$ Therefore, the efficacy of single-dose del Nido cardioplegia in children could be related in part to the patient population rather than the cardioplegia solution itself. Although some centers are using del Nido cardioplegia in adults with single dosing or long intervals between doses (60-120 min), it remains to be determined if multiple dosing with del Nido cardioplegia could provide additional benefits in mature or aged hearts, and what the optimal re-administration volume or interval would be. It should be kept in mind that the administration of large volumes of del Nido cardioplegia could result in increased systemic lidocaine levels that may be a safety issue, particularly in patients with impaired renal function. ${ }^{36}$

\section{Limitations}

The isolated heart model used in this study had several limitations that must be considered when interpreting our results. The isolated working heart preparation is viable for only a limited time. Although it is possible to examine cardiac function in the short term with this system, it is not feasible to study hearts at more clinically relevant time points (12 or 24 hours after reperfusion). The hearts in this study were exposed to ambient room temperature during the ischemic period, which would limit re-warming compared with the clinical situation in which systemic temperature is usually higher. Furthermore, the isolated heart is not subject to noncoronary collateral flow during the ischemic period, which might alter the efficacy of the myocardial protection strategy by washing out the cardioplegia and/or rewarming the myocardium. The volume of autologous blood that we can collect from each rat is limited. With 4:1 cardioplegia we are able to prepare the induction dose plus 2 additional doses, which allows a maximum 60-minute ischemic period if re-dosing occurs every 20 minutes. If longer ischemic periods were possible, benefits with del Nido cardioplegia might become less apparent if the single-dose strategy becomes inadequate with prolonged cross-clamp times. Although ischemiareperfusion injury is initiated primarily by $\mathrm{Ca}^{2+}$ overload, other processes affect the development of myocardial injury and evolution of functional recovery. For example, the inflammatory system plays a role in the myocardial damage that occurs early after reperfusion. ${ }^{37}$ Most of these limitations need to be addressed in future studies in intact animals.

\section{CONCLUSIONS}

We have shown that in isolated elderly hearts, a del Nido cardioplegia strategy is associated with less spontaneous activity during arrest, reduced myocardial injury, and improved functional recovery when compared with a standard multidose 4:1 blood cardioplegia strategy. Additional studies in a whole animal will help to determine if these results persist in a more clinically relevant model, and justify clinical studies in elderly patients undergoing cardiac surgery.

The authors wish to thank Richard Livingston for his technical support and Karen Buth for statistical support. 


\section{References}

1. Hirose H, Amano A, Yoshida S, Takahashi A, Nagano N, Kohmoto T. Coronary artery bypass grafting in the elderly. Chest. 2000;117:1262-70.

2. Shahian DM, O'Brien SM, Filardo G, Ferraris VA, Haan CK, Rich JB, et al. The Society of Thoracic Surgeons 2008 cardiac surgery risk models: part 1-coronary artery bypass grafting surgery. Ann Thorac Surg. 2009;88(Suppl): S2-22.

3. McCully JD, Toyoda Y, Wakiyama H, Rousou AJ, Parker RA, Levitsky S. Ageand gender-related differences in ischemia/reperfusion injury and cardioprotection: effects of diazoxide. Ann Thorac Surg. 2006;82:117-23.

4. Willems L, Zatta A, Holmgren K, Ashton KJ, Headrick JP. Age-related changes in ischemic tolerance in male and female mouse hearts. J Mol Cell Cardiol. 2005; 38:245-56.

5. Ataka K, Chen D, Levitsky S, Jimenez E, Feinberg H. Effect of aging on intracellular $\mathrm{Ca} 2+$, pHi, and contractility during ischemia and reperfusion. Circulation. 1992;86(Suppl):II371-6.

6. O'Brien JD, Ferguson JH, Howlett SE. Effects of ischemia and reperfusion on isolated ventricular myocytes from young adult and aged Fischer 344 rat hearts. Am J Physiol Heart Circ Physiol. 2008;294:H2174-83.

7. Faulk EA, McCully JD, Hadlow NC, Tsukube T, Krukenkamp IB, Federman M, et al. Magnesium cardioplegia enhances mRNA levels and the maximal velocity of cytochrome oxidase I in the senescent myocardium during global ischemia. Circulation. 1995;92(Suppl):II405-12.

8. Tsukube T, McCully JD, Metz KR, Cook CU, Levitsky S. Amelioration of ischemic calcium overload correlates with high-energy phosphates in senescent myocardium. Am J Physiol. 1997;273:H418-25.

9. O’Brien JD, Howlett SE, Burton HJ, O'Blenes SB, Litz DS, Friesen CL. Pediatric cardioplegia strategy results in enhanced calcium metabolism and lower serum troponin T. Ann Thorac Surg. 2009;87:1517-23.

10. Matte GS, del Nido PJ. History and use of del Nido cardioplegia solution at Boston Children's Hospital. J Extra Corpor Technol. 2012;44:98-103.

11. Charette K, Gerrah R, Quaegebeur J, Chen J, Riley D, Mongero L, et al. Single dose myocardial protection technique utilizing del Nido cardioplegia solution during congenital heart surgery procedures. Perfusion. 2012;27: 98-103.

12. Aoki M, Nomura F, Kawata H, Mayer JE Jr. Effect of calcium and preischemic hypothermia on recovery of myocardial function after cardioplegic ischemia in neonatal lambs. J Thorac Cardiovasc Surg. 1993;105:207-12.

13. Bolling K, Kronon M, Allen BS, Ramon S, Wang T, Hartz RS, et al. Myocardial protection in normal and hypoxically stressed neonatal hearts: the superiority of hypocalcemic versus normocalcemic blood cardioplegia. J Thorac Cardiovasc Surg. 1996;112:1193-200.

14. Corno AF, Bethencourt DM, Laks H, Haas GS, Bhuta S, Davtyan HG, et al. Myocardial protection in the neonatal heart. A comparison of topical hypothermia and crystalloid and blood cardioplegic solutions. J Thorac Cardiovasc Surg. 1987;93:163-72.

15. O'Blenes SB, Friesen CH, Ali A, Howlett S. Protecting the aged heart during cardiac surgery: the potential benefits of del Nido cardioplegia. $J$ Thorac Cardiovasc Surg. 2011;141:762-70.

16. Piper HM, Garcia-Dorado D. Prime causes of rapid cardiomyocyte death during reperfusion. Ann Thorac Surg. 1999;68:1913-9.

17. Allen DG, Cairns SP, Turvey SE, Lee JA. Intracellular calcium and myocardial function during ischemia. Adv Exp Med Biol. 1993;346:19-29.

18. Attwell D, Cohen I, Eisner D, Ohba M, Ojeda C. The steady state TTX-sensitive ("window") sodium current in cardiac Purkinje fibres. Pflugers Arch. 1979;379: 137-42.

19. Chambers DJ. Mechanisms and alternative methods of achieving cardiac arrest. Ann Thorac Surg. 2003;75:S661-6.

20. Chambers DJ, Hearse DJ. Developments in cardioprotection: "polarized" arrest as an alternative to "depolarized" arrest. Ann Thorac Surg. 1999;68:1960-6.

21. Canadian Council on Animal Care. In: Olfert ED, Cross BM, McWilliam AA, eds. Guide to care and use of experimental animals. Vol 1. 2nd ed. Ottawa, Canada: Canadian Council on Animal Care; 1993. Available at: http://ccac.ca/ Documents/Standards/Guidelines/Experimental_Animals_Vol1.pdf.

22. Rudd DM, Dobson GP. Toward a new cold and warm nondepolarizing, normokalemic arrest paradigm for orthotopic heart transplantation. $J$ Thorac Cardiovasc Surg. 2009; 137:198-207.

23. Tsukube T, McCully JD, Federman M, Krukenkamp IB, Levitsky S. Developmental differences in cytosolic calcium accumulation associated with surgically induced global ischemia: optimization of cardioplegic protection and mechanism of action. J Thorac Cardiovasc Surg. 1996;112:175-84.
24. Caldarone CA, Krukenkamp IB, Burns PG, Gaudette GR, Schulman J, Levitsky S. Blood cardioplegia in the senescent heart. J Thorac Cardiovasc Surg. 1995;109:269-74.

25. Turturro A, Witt WW, Lewis S, Hass BS, Lipman RD, Hart RW. Growth curves and survival characteristics of the animals used in the biomarkers of aging program. J Gerontol A Biol Sci Med Sci. 1999;54:B492-501.

26. Teoh KH, Christakis GT, Weisel RD, Fremes SE, Mickle DA, Romaschin AD et al. Accelerated myocardial metabolic recovery with terminal warm blood cardioplegia. J Thorac Cardiovasc Surg. 1986;91:888-95.

27. Belardinelli L, Antzelevitch C, Fraser H. Inhibition of late (sustained/persistent) sodium current: a potential drug target to reduce intracellular sodium-dependen calcium overload and its detrimental effects on cardiomyocyte function. Eur Heart J Suppl. 2004;6:13-7.

28. Belardinelli L, Shryock JC, Fraser H. Inhibition of the late sodium current as a potential cardioprotective principle: effects of the late sodium current inhibitor ranolazine. Heart. 2006;92(Suppl 4):iv6-14.

29. Perlmutter NS, Wilson RA, Edgar SW, Sanders W, Greenberg BH, Tanz R. Vasodilatory effects of lidocaine on epicardial porcine coronary arteries. Pharmacology. 1990;41:280-5.

30. Sakai A, Miya J, Sohara Y, Maeta H, Ohshima N, Hori M. Role of red blood cells in the coronary microcirculation during cold blood cardioplegia. Cardiovasc Res. 1988;22:62-6.

31. Fremes SE, Christakis GT, Weisel RD, Mickle DA, Madonik MM, Ivanov J, et al A clinical trial of blood and crystalloid cardioplegia. J Thorac Cardiovasc Surg. 1984;88:726-41.

32. Ibrahim MF, Venn GE, Young CP, Chambers DJ. A clinical comparative study between crystalloid and blood based St Thomas' hospital cardioplegic solution. Eur J Cardiothorac Surg. 1999;15:75-83.

33. O'Neill MJ, Francalancia N, Wolf PD, Parr GV, Waldhausen JA. Resistance differences between blood and crystalloid cardioplegic solutions with myocardial cooling. J Surg Res. 1981;30:354-60.

34. Buckberg GD. Update on current techniques of myocardial protection Ann Thorac Surg. 1995;60:805-14.

35. Magovern JA, Pae WE, Waldhausen JA. Protection of the immature myocardium An experimental evaluation of topical cooling, singe-dose, and multiple-dose administration of St Thomas' Hospital cardioplegic solution. J Thorac Cardiovasc Surg. 1988;96:408-13.

36. Yamaguchi S, Watanabe G, Tomita S, Tabata S. Lidocaine-magnesium blood cardioplegia was equivalent to potassium blood cardioplegia in left ventricular function of canine heart. Interact Cardiovasc Thorac Surg. 2007;6:172-6.

37. Frangogiannis NG, Smith CW, Entman ML. The inflammatory response in myocardial infarction. Cardiovasc Res. 2002;53:31-47.

\section{Discussion}

Dr J. William Gaynor (Philadelphia, Pa). I would like to congratulate the authors on a very nice study and an excellent presentation. It is always nice to discuss a paper that agrees with your own beliefs.

We switched to del Nido at the Children's Hospital in Philadelphia several years ago, and we currently use it for all of our patients from neonates to the young adults. We do not have elderly patients very frequently at $\mathrm{CHOP}$, but we do go into the 30- and 40-year-olds.

Our clinical experience mimics this completely. We usually use a single dose. We see very little return of spontaneous activity, and we have been very happy with the postoperative function.

That being said, when we retrospectively compared our early outcomes, inotropic use, and everything to our previous crystalloid cardioplegia, we could show no differences. So our anecdotal experience is that we like it, it seems to facilitate the operation by only having to give one dose, we do see less spontaneous activity, but we cannot show a clinical difference.

Now, when you go to, as you mentioned in your future directions, you move to elderly patients, you are going to be dealing with myocardium that is ischemic or perhaps has been 
subjected to long-term pressure volume overload or in a redo situation. So how do we move forward from this isolated heart model of essentially elderly but normal myocardium to a clinical trial where we can actually show a difference? Because I am afraid it would take so many patients as to become not feasible to perform that study. But that being said, we use del Nido, we are very happy with it, and we do think it is a better myocardial protective strategy.

Thank you very much. I enjoyed your paper.

Mr Govindapillai. Thank you, Dr Gaynor. To try and answer your question, I think that what needs to happen is we need to look at a whole animal model first. There are some concerns in terms of single dosing with del Nido with adult patients where procedures can be pretty long and so sometimes re-dosing can occur over longer intervals than with our standard cardioplegia where it is given in shorter intervals. But I think certainly the next step would be to look at a whole animal model and see where the inflammatory system plays a role as well and that would be, to me, the next logical step before you can move on to some sort of a clinical trial, and hopefully we can see some differences there as well.

Dr Gaynor. We occasionally use multidose if we have a particularly long cross-clamp or in the rare case where we do see a return of activity, and it works very well if you give an additional dose. But again, I think I agree with the findings, I think it is an excellent protective strategy, I think it probably is applicable to a wider range of patients, but I do think it is going to be very hard to prove that in a clinical setting.

Thank you very much.

Mr Govindapillai. Thank you. 